Article

\title{
A Green Method for Processing Polymers using Dense Gas Technology
}

Roshan B. Yoganathan $^{1, \star}$, Raffaella Mammucari ${ }^{2}$ and Neil R. Foster $^{2}$

${ }^{1}$ Department of Pharmaceutical Sciences, Leslie Dan Faculty of Pharmacy, University of Toronto, 144 College Street, Toronto, Ontario M5S 3M2, Canada

${ }^{2}$ School of Chemical Engineering, Chemical Sciences Building, University of New South Wales, Sydney NSW 2052, Australia

* Author to whom correspondence should be addressed; E-Mail: roshan.yoganathan @utoronto.ca; Tel.: (+1) 416-946-0040; Fax: (+1) 416-978-8511.

Received: 29 March 2010; in revised form: 27 April 2010 / Accepted: 6 May 2010 /

Published: 11 May 2010

\begin{abstract}
Dense $\mathrm{CO}_{2}$ can be used as an environmentally-benign polymer processing medium because of its liquid-like densities and gas-like mass transfer properties.In this work, polymer bio-blends of polycarbonate (PC), a biocompatible polymer, and polycaprolactone (PCL), a biodegradable polymer were prepared. Dense $\mathrm{CO}_{2}$ was used as a reaction medium for the melt-phase PC polymerization in the presence of dense $\mathrm{CO}_{2}$-swollen PCL particles and this method was used to prepare porous PC/PCL blends. To extend the applicability of dense $\mathrm{CO}_{2}$ to the biomedical industry and polymer blend processing, the impregnation of ibuprofen into the blend was conducted and subsequent dissolution characteristics were observed.
\end{abstract}

Keywords: dense gas technology; polymer processing; green technology; biomedical polymers; drug delivery system; polymer blends; polymerization; polycarbonate; polycaprolactone; ibuprofen 


\section{Introduction}

\subsection{Polycarbonates}

An aromatic polycarbonate (PC) such as bisphenol-A (BPA) PC, possess strong mechanical properties, heat resistance and unique optical clarity. Aromatic PC have been used in the medical field in filter cartridges for renal dialysis, blood-management products, surgical instruments, and intravenous connection components [1]. The conventional synthesis of PC involves the use of phosgene $\left(\mathrm{COCl}_{2}\right)$, an environmentally hazardous and toxic substance. Phosgene poses an occupational risk and once released in the form of manufacturing waste, it is an environmental hazard. Acute and chronic effects of phosgene exposure can be as severe as liver failure and lung damage. Consequently, health-related and environmental regulations have been imposed on the polymer industry regarding the use of phosgene [2,3]. One phosgene-free method of PC synthesis is the transesterification of BPA and diphenyl carbonate (DPC) (Figure 1), a type of polycondensation reaction with phenol as the by-product. Few environmentally benign methods of $\mathrm{PC}$ synthesis involving dense $\mathrm{CO}_{2}$ have been documented [2,4-7].

Figure 1. Synthesis of polycarbonate by the transesterification of bisphenol-A.

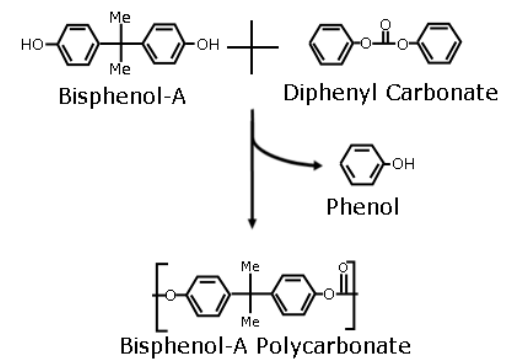

Polycarbonate Synthesis in Dense $\mathrm{CO}_{2}$

Carbon dioxide has been used in heterogeneous polymerizations of PC such as dense gas (DG) melt-phase polymerization, solid-state polymerization (SSP) and dispersion polymerization [4-6]. In all cases, $\mathrm{CO}_{2}$ was used to extract phenol, which is highly soluble in dense $\mathrm{CO}_{2}$. As the phenol is extracted, the synthesis is driven towards the formation of higher molecular weight PC [8]. The transesterification of BPA and DPC was conducted in the melt phase and $\mathrm{CO}_{2}$ was used to extract the by-product $[4,5]$. In another method, Gross et al. reported that SSP was most effective on PC particles when using $\mathrm{CO}_{2}$ [5]. Particles $20 \mu \mathrm{m}$ in size underwent SSP to produce PC with weight-average molecular weight $\left(\mathrm{M}_{w}\right)$ of $1.75 \times 10^{4} \mathrm{Da}$ whereas particles $3.6 \mathrm{~mm}$ in size produced PC of $\mathrm{M}_{w} 7.5 \times 10^{3} \mathrm{Da}$. For SSP conducted in dense $\mathrm{CO}_{2}$ the particle size and available surface area have an effect on the $\mathrm{M}_{w}$ of the polymer. Decreased particle size provides a larger surface area for dense $\mathrm{CO}_{2}$ to interact with and extract phenol, and corresponds to higher $\mathrm{M}_{w}$ PC. Also, dispersion polymerization $\left(\mathrm{CO}_{2}\right.$ as dispersing phase) produced PC nanoparticles with $\mathrm{M}_{w} 3.0 \times 10^{5}$ Da by tuning the surfactant concentration, $\mathrm{CO}_{2}$ pressure and temperature [6]. In the aforementioned studies, dense $\mathrm{CO}_{2}$ was used successfully to synthesize PC, thereby circumventing the use of phosgene. 


\subsection{Polycaprolactone}

Polycaprolactone is a well-known biodegradable polymer widely used in the biomedical field. It is commonly used for tissue engineering applications because of its favourable and prolonged rate of degradation in vivo [9]. Dense gas processing of PCL has been used to foam the polymer and create micro and nano-architectures in it $[10,11]$.

\subsection{Polymer Blends}

Bio-blends (blends involving at least one biodegradable component) are gaining wide interest in the biomedical field for drug delivery devices and implantable/non-implantable formulations, and in the agricultural field for materials/packaging applications [12-14]. Conventional blending techniques, such as solvent casting and melt extrusion use toxic solvents or are conducted at high temperatures [15-18]. The dense gas technology (DGT) can provide polymer synthesis and polymer blend processing methods void of toxic solvents and low temperature operation. According to Tomasko et al. the next wave of dense $\mathrm{CO}_{2}$ polymer processing applications is in the field of polymer blends [19].

In studies reported in the literature, dense $\mathrm{CO}_{2}$-swollen polymers have been impregnated with monomers and subsequent polymerization reactions were conducted to produce polymer blends. Watkins et al. [20-23] and $\mathrm{Li}$ et al. [23] conducted the free radical polymerization of styrene in dense $\mathrm{CO}_{2}$-swollen polyethylene (PE) to create polystyrene (PS)/PE blends . Dense $\mathrm{CO}_{2}$ has been used to increase the compatibility of immiscible polymer blends, thereby creating fine dispersed domains $[19,24,25]$.

Polymer blends of PC/PCL have potential industrial and biomedical applications both in vivo and in vitro. The biodegradability of PCL has long been exploited to culture biological components. The applicability of PCL can be extended and its mechanical properties enhanced by creating a bio-blend with a stronger polymer such as PC. The use of dense $\mathrm{CO}_{2}$ as a bio-blend processing medium was investigated in this work.

In some cases, PC/PCL blends have proved to be miscible over the entire composition range [26-30]. Dense gas technology can be used to create PC/PCL bio-blends by synthesizing PC in the presence of dense $\mathrm{CO}_{2}$-swollen PCL. Although, the dense $\mathrm{CO}_{2}$-swollen polymers are usually the major component of blends prepared by DGT, in this work PCL was the minor component.

In this study, a dense $\mathrm{CO}_{2}$ melt polymerization of BPA and DPC was conducted to prove the applicability of $\mathrm{CO}_{2}$ as a polymerization medium for the production of an aromatic PC (BPA-PC). Dense $\mathrm{CO}_{2}$ was also used as an extraction medium to flush out the $\mathrm{CO}_{2}$-soluble by-product phenol. Sodium hydroxide $(\mathrm{NaOH})$, a cheap and relatively safe catalyst, was used for the dense $\mathrm{CO}_{2}$ melt polymerization .

Polycarbonate samples were analyzed using reverse-phase high performance liquid chromatography (RP-HPLC), electron spray ionization-mass spectrometry (ESI-MS) and gel permeation chromatography (GPC). A RP-HPLC method was developed to measure the conversion of BPA for the preliminary melt polymerization experiments. The MS technique was used to validate the PC structure for preliminary molecular weight determination. The GPC was used to obtain polymer molecular weight.The melt-phase $\mathrm{PC}$ synthesis was then conducted in the presence of dense $\mathrm{CO}_{2}$-swollen PCL particles producing porous PC/PCL blends. The impregnation of ibuprofen using dense $\mathrm{CO}_{2}$ was also carried out on PCL and DG 
processed bio-blends. Subsequent dissolution studies were used to measure the drug-release properties of the samples.

\section{Materials and Methods}

Bisphenol A (99\% purity), DPC (99\% purity), $\mathrm{NaOH}$ (99\% purity), PCL ( $\mathrm{M}_{w}=1.2 \times 10^{4} \mathrm{Da}$, 99\% purity) and tin(II)ethyl hexanoate $\left(\mathrm{Sn}\left(\mathrm{Oct}_{2}\right)\right)$ (95\% purity) were used as received from Sigma Aldrich. The PCL monomer, $\varepsilon$ CL (99\% purity) was purchased from Fluka. Ibuprofen was supplied by Nanomaterials Technology (Singapore). Cylinders of compressed $\mathrm{N}_{2}$ grade 3.0 and compressed $\mathrm{CO}_{2}$ grade 2.5 were used as supplied by Linde.

Materials were loaded into a high pressure vessel with an internal volume of $10 \mathrm{~mL}$ as depicted in Figure 2 . The reactor was placed in a temperature-controlled oil bath and its content was magnetically stirred. Pressure and temperature were monitored by a Druck DPI 260 pressure transducer and WiseStir MSH-20D thermocouple, respectively.

Figure 2. High pressure vessel setup.

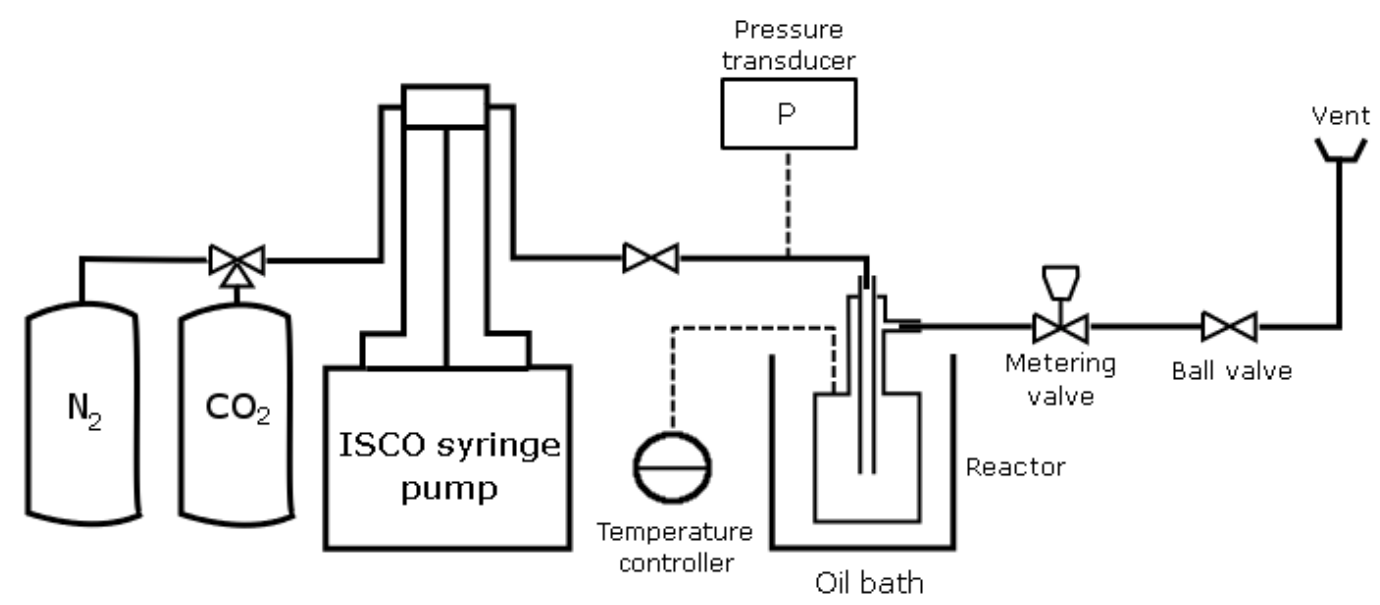

The PC synthesis experiments were carried out in an inert environment $\left(\mathrm{N}_{2}\right)$ with varying reaction times. Preliminary experiments with monomer to catalyst mole ratios of 1:1 and 2:1 caused hydrolysis reactions that inhibited the polymerization. A monomer to catalyst mass ratio of 100:1 which is equivalent to a BPA:DPC:NaOH mass ratio of 50:50:1 was used for all experiments. The operating pressure of $\mathrm{N}_{2}$ was 1 bar. At the end of each experiment, the reactor was cooled in cold water.

\subsection{Two-stage PC Synthesis in $\mathrm{N}_{2}$ and $\mathrm{CO}_{2}$}

Two-stage experiments were conducted under 1 bar $\mathrm{N}_{2}$ in an isolated reactor (Stage 1) and then flushed with a continuous flow of 200 bar dense $\mathrm{CO}_{2}$ (Stage 2). The continuous flow of dense $\mathrm{CO}_{2}$ was introduced to help extract the phenol. All experiments were conducted in the melt phase. The dense $\mathrm{CO}_{2}$ flow-rates were controlled using a metering valve. 


\subsection{Three-stage PC Synthesis}

The three-stage PC synthesis experiments were conducted using the setup in Figure 2. Operating conditions depicted in Figure 3 were used.

Figure 3. Three stages for the production of sample PC-6 hrs.

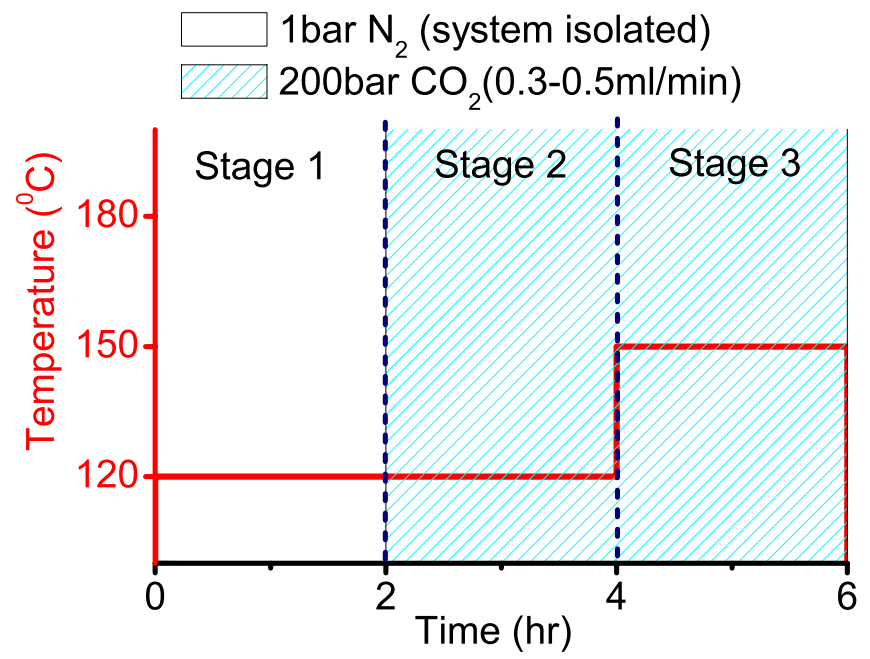

\subsection{Synthesis of PC With Dense $\mathrm{CO}_{2}$-foamed PCL}

Bisphenol A, and DPC were ground together in equivalent molar ratios, and then placed in the high pressure reactor (Figure 2) with the catalyst (Table 1). Polycaprolactone from Sigma was ground separately using a mortar and pestle, and then loaded into the same $10 \mathrm{~mL}$ high pressure reactor. Samples were subjected to the experimental method depicted in Figure 3. All samples were analyzed using TGA, DSC, scanning electron microscopy (SEM), and BET nitrogen adsorption.

Table 1. Sample composition for PC synthesis in dense $\mathrm{CO}_{2}$-foamed PCL.

\begin{tabular}{lc}
\hline Sample & Mass Ratio \\
\hline PC80/PCL20 & 200mg BPA : 200mg DPC : 4mg NaOH : 100mg PCL \\
PC75/PCL25 & 150mg BPA : 150mg DPC : 3mg NaOH : 100mg PCL \\
PC67/PCL33 & 100mg BPA : 100mg DPC : 2mg NaOH : 100mg PCL \\
PCL & PCL only \\
\hline
\end{tabular}

\subsection{Impregnation of PC/PCL Blend}

Sample PC67/PCL33 (Table 1) underwent an impregnation with ibuprofen, followed by a dissolution study. The PC67/PCL33 sample was placed in a $5 \mathrm{ml}$ beaker and loaded alongside another beaker with excess ibuprofen inside a $100 \mathrm{~mL}$ temperature-controlled stainless steel reactor. The $4 \mathrm{hr}$ experiment was conducted at $40^{\circ} \mathrm{C}$ and 200 bar. Also, a control experiment with PCL from Sigma was conducted. 


\subsection{Analytical Techniques}

Gel Permeation Chromatography

Gel permeation chromatograms were obtained using a Shimadzu GPC with tetrahydrofuran (THF) as the mobile phase. The GPC was calibrated using PS standards. Mark-Houwink parameters ( $\mathrm{K}=40 \times 10^{3}, \alpha=0.7$ ) were used to relate the viscosity of PC in THF to the PS standards used for THF GPC calibration [31].

\section{Differential Scanning Calorimetry}

A TA Instruments DSC 2010 Differential Scanning Calorimeter was used with $\mathrm{N}_{2}$ gas flow, and a gradient of $20{ }^{\circ} \mathrm{C} / \mathrm{min}$ from $-100{ }^{\circ} \mathrm{C}$ up to $200{ }^{\circ} \mathrm{C}$.

Scanning Electron Microscopy

A Hitachi S3400i was used to take images of the PC/PCL blends (Table 1).

Nitrogen Adsorption

Porosity analysis of the PC/PCL blends (Table 1) was conducted on a Micromeritics TriStar 3000 Analyzer using nitrogen adsorption.

Reverse-phase High Performance Liquid Chromatography

Reverse-phase high performance liquid chromatography was used to quantify the drug-loading of ibuprofen. The PC monomers had a similar UV absorbance to the ibuprofen, therefore a RP-HPLC method was developed to separate the compounds. A RP-HPLC method was developed on a Waters system which included a 717 plus autosampler and a 515 HPLC pump. The system was equipped with a Waters 996 photodiode array detector. A Lichrosorb RP18 analytical column from Phase Separations was housed in an Activon column oven at $60{ }^{\circ} \mathrm{C}$. The starting mobile phase was $10 \% \mathrm{THF} / 90 \%$ deionized water at a flow-rate of $1.5 \mathrm{~mL} / \mathrm{min}$. After $150 \mathrm{~min}$ the mobile phase was changed to $50 \%$ $\mathrm{THF} / 50 \%$ deionized water over a period of $15 \mathrm{~min}$. The RP-HPLC system was also used to construct a calibration curve for ibuprofen. The calibration was obtained using an isocratic mobile phase of $10 \%$ THF/90\% deionized water.

\section{Dissolution Study}

Powder dissolution studies were performed under sink conditions for ibuprofen. The dissolution studies used the paddle method in $100 \mathrm{~mL}$ deionized water at $37{ }^{\circ} \mathrm{C}$ and stirring at $50 \mathrm{rpm}$. Aliquots of $4 \mathrm{~mL}$ were withdrawn at specific time intervals. The concentration of ibuprofen was quantified using a UV spectrophotometer at an absorbance of $220 \mathrm{~nm}$. 


\section{Results and Discussion}

\subsection{PC Synthesis}

As reported in Table 2, experiments conducted at $200{ }^{\circ} \mathrm{C}$ did not produce higher $\mathrm{M}_{w}$ PC than the experiments conducted at $120{ }^{\circ} \mathrm{C}$ and $150{ }^{\circ} \mathrm{C}$. None of the PC prepolymer synthesized in $\mathrm{N}_{2}$ exceeded a $\mathrm{M}_{w}$ of $1.5 \times 10^{3} \mathrm{Da}$. The experiments under $\mathrm{N}_{2}$ were conducted in a isolated system resulting in the accumulation of phenol, which in turn slowed down the generation of higher $\mathbf{M}_{w}$ PC. The experiments conducted at $120{ }^{\circ} \mathrm{C}$ produced the highest $\mathrm{M}_{w}$. Of the tested conditions (Table 2), $120{ }^{\circ} \mathrm{C}$ was the most favourable operating condition, whilst increasing the reaction time over hours did not improve the $\mathbf{M}_{w}$.

Comparison between the $\mathrm{M}_{w}$ of samples PC- 6 hrs $\left(3.9 \times 10^{3} \mathrm{Da}\right)$ from Table 6 to the $\mathrm{M}_{w}$ of sample $\mathrm{N}_{2}$-2- $\mathrm{CO}_{2}-4-120\left(2.56 \times 10^{3} \mathrm{Da}\right)$ from Table 5 shows the effectiveness of the three-stage polymer synthesis method over the two-stage methods. The use of a multi-stage PC synthesis method was derived from the aforementioned results and results reported by Kiserow and co-workers [5,32], and Lee et al. [6]. Results from Table 4, 5 and 6 reflect the effectiveness of a multi-stage prepolymer synthesis approach for $10 \% \mathrm{w} / \mathrm{w}$ catalyst to monomers, with varying temperature, dense $\mathrm{CO}_{2}$ pressure and a set dense $\mathrm{CO}_{2}$ flow-rate of $0.3-0.5 \mathrm{~mL} / \mathrm{min}$.

Table 2. PC synthesis in $\mathrm{N}_{2}$.

\begin{tabular}{lrrccc}
\hline Sample & $\begin{array}{r}\text { Time } \\
(\mathrm{hr})\end{array}$ & $\begin{array}{r}\text { Temp } \\
\left({ }^{\circ} \mathrm{C}\right)\end{array}$ & $\begin{array}{c}\mathrm{M}_{w} \times 10^{3} \\
(\mathrm{Da})\end{array}$ & $\begin{array}{c}\text { BPA Conv } \\
(\%)\end{array}$ & $\begin{array}{c}\text { DPC Conv } \\
(\%)\end{array}$ \\
\hline $\mathrm{N}_{2}-1-120$ & 1 & 120 & 1.18 & 78.3 & 81.3 \\
$\mathrm{~N}_{2}-4-120$ & 4 & 120 & 1.26 & 79.3 & 81.9 \\
$\mathrm{~N}_{2}-12-120$ & 12 & 120 & 1.20 & 79.5 & 85.8 \\
\hline $\mathrm{N}_{2}-1-150$ & 1 & 150 & 0.90 & 80.1 & 82.4 \\
$\mathrm{~N}_{2}-4-150$ & 4 & 150 & 0.99 & 98.9 & 99.4 \\
$\mathrm{~N}_{2}-8-150$ & 8 & 150 & 0.92 & 98.9 & 99.4 \\
$\mathrm{~N}_{2}-24-150$ & 24 & 150 & 1.00 & 82.0 & N/A \\
$\mathrm{N}_{2}-48-150$ & 48 & 150 & 0.90 & 86.0 & 89.8 \\
\hline $\mathrm{N}_{2}-1-200$ & 1 & 200 & 0.75 & 81.0 & N/A \\
$\mathrm{N}_{2}-4-200$ & 4 & 200 & 0.78 & 84.9 & 99.7 \\
$\mathrm{~N}_{2}-48-200$ & 48 & 200 & 0.90 & 86.3 & 99.9 \\
\hline
\end{tabular}

The three stages $6 \mathrm{hr}$ PC synthesis method produced a PC with a $\mathrm{M}_{w}$ of $3.9 \times 10^{3} \mathrm{Da}$. The third stage $150{ }^{\circ} \mathrm{C}, 200$ bar with a dense $\mathrm{CO}_{2}$ flux has shown to increase the $\mathrm{M}_{w}$ when compared to the two-stage process $\mathrm{N}_{2}-2-\mathrm{CO}_{2}-4-120\left(\mathrm{M}_{w}=2.56 \times 10^{3} \mathrm{Da}\right)$. Results with this work are in line with both Lee et al. [6] and Kiserow and co-workers [5,32] on the effectiveness of phenol extraction by dense $\mathrm{CO}_{2}$.

The PC synthesis in this work has produced a polymer with $\mathbf{M}_{w}$ comparable to other dense gas processes. The three-stage PC synthesis procedure used in this work used a lower amount of catalyst and organic solvents than conventional methods. 
Table 3. $\mathrm{M}_{w}$ based on GPC and ESI-MS.

\begin{tabular}{lcc}
\hline Sample & GPC & ESI-MS \\
& $\mathrm{M}_{w} \times 10^{3}(\mathrm{Da})$ & $\mathrm{M}_{w} \times 10^{3}(\mathrm{Da})$ \\
\hline $\mathrm{N}_{2}-24-150$ & 1.00 & 0.94 \\
$\mathrm{~N}_{2}-48-150$ & 0.90 & 0.92 \\
$\mathrm{~N}_{2}-1-200$ & 0.75 & 0.87 \\
\hline
\end{tabular}

Table 4. GPC results for PC synthesis in $\mathrm{N}_{2}$ and $\mathrm{CO}_{2}$ at $150{ }^{\circ} \mathrm{C}$. Two-stage process.

\begin{tabular}{lcccc}
\hline Sample & $\begin{array}{c}\text { Stage 1 time } \\
\mathrm{N}_{2}(\mathrm{hrs})^{\dagger}\end{array}$ & $\begin{array}{c}\text { Stage 2 time } \\
\mathrm{CO}_{2}(\mathrm{hrs})^{\natural}\end{array}$ & $\begin{array}{c}\text { Total } \\
(\mathrm{hrs})\end{array}$ & $\begin{array}{c}\mathrm{M}_{w} \times 10^{3} \\
(\mathrm{Da})\end{array}$ \\
\hline $\mathrm{N}_{2}-2-\mathrm{CO}_{2}-2$ & 2 & 2 & 4 & 1.40 \\
$\mathrm{~N}_{2}-4$ & 4 & 0 & 0 & 0.99 \\
$\mathrm{~N}_{2}-4-\mathrm{CO}_{2}-1$ & 4 & 1 & 5 & 1.33 \\
$\mathrm{~N}_{2}-4-\mathrm{CO}_{2}-4$ & 4 & 4 & 8 & 2.60 \\
$\mathrm{~N}_{2}-4-\mathrm{CO}_{2}-8$ & 4 & 8 & 12 & 1.48 \\
\hline${ }^{\dagger}=$ isolated at 1 bar & & & \\
${ }^{\natural}=100$ bar with a flow-rate of $2 \mathrm{~mL} / \mathrm{min}$ & &
\end{tabular}

Table 5. GPC results for PC synthesis in $\mathrm{N}_{2}$ and $\mathrm{CO}_{2}$ at $120{ }^{\circ} \mathrm{C}$. Two-stage process.

\begin{tabular}{lcccc}
\hline Sample & $\begin{array}{c}\text { Stage 1 time } \\
(\mathrm{hrs})^{\dagger}\end{array}$ & $\begin{array}{c}\text { Stage 2 time } \\
(\mathrm{hrs})^{\ddagger}\end{array}$ & $\begin{array}{c}\text { Total } \\
(\mathrm{hrs})\end{array}$ & $\begin{array}{c}\mathrm{M}_{w} \times 10^{3} \\
(\mathrm{Da})\end{array}$ \\
\hline $\mathrm{N}_{2}-2-120$ & 2 & 0 & 2 & 1.28 \\
$\mathrm{~N}_{2}-2-\mathrm{CO}_{2}-2-120$ & 2 & 2 & 4 & 1.82 \\
$\mathrm{~N}_{2}-2-\mathrm{CO}_{2}-4-120$ & 2 & 4 & 6 & 2.56 \\
$\mathrm{~N}_{2}-4-\mathrm{CO}_{2}-8-120$ & 2 & 8 & 10 & 4.73 \\
\hline${ }^{\dagger}=$ isolated at 1 bar & & & \\
$\ddagger=$ 200 bar with a flow-rate of $0.3-0.5 \mathrm{~mL} / \mathrm{min}$ & &
\end{tabular}

Table 6. GPC results for the three-stage PC synthesis at $120{ }^{\circ} \mathrm{C}$.

\begin{tabular}{lcccc}
\hline Sample & Stage 1 (hrs) & Stage 2 (hrs) & Stage 3 (hrs) & $\mathrm{M}_{w} \times 10^{3}(\mathrm{Da})$ \\
\hline PC-6hrs & 2 & 2 & 2 & 3.9 \\
PC-8hrs & 4 & 2 & 2 & 3.8 \\
PC-8hrs-stage3 & 2 & 2 & 4 & 4.7 \\
\hline
\end{tabular}




\subsection{Synthesis of $\mathrm{PC}$ with Dense $\mathrm{CO}_{2}$-foamed $\mathrm{PCL}$}

The PC/PCL DSC profiles and their corresponding $\mathrm{T}_{g}$ values can be found in Figure 5 and Table 7, respectively. Within the depicted temperature range, only PC67/PCL33 had a broad endothermic transition characteristic of a $\mathrm{T}_{m}$ at $155^{\circ} \mathrm{C}$. The $\mathrm{T}_{g}$ values for the PC/PCL blends are all similar, and higher than the $\mathrm{T}_{g}$ of PCL $\left(-60^{\circ} \mathrm{C}\right.$ ) (Figure 4). The composition-dependent shifting of a $\mathrm{T}_{g}$ correspond to samples with intimate level of blending. The $\mathrm{T}_{m}$ of PCL at $60{ }^{\circ} \mathrm{C}$ and $\mathrm{T}_{g}$ of $\mathrm{PC}$ at $145{ }^{\circ} \mathrm{C}$ were not observed in the DSC profiles of the blends. The DSC profiles of all the samples (Figure 5) support the existence of a strong interaction between PC and PCL. In particular, the absence of $\mathrm{T}_{m}$ and the shifting of the $\mathrm{T}_{g}$ indicates intimate and molecular blending [33].

Figure 4. DSC profiles of PC and PCL (exothermic up).

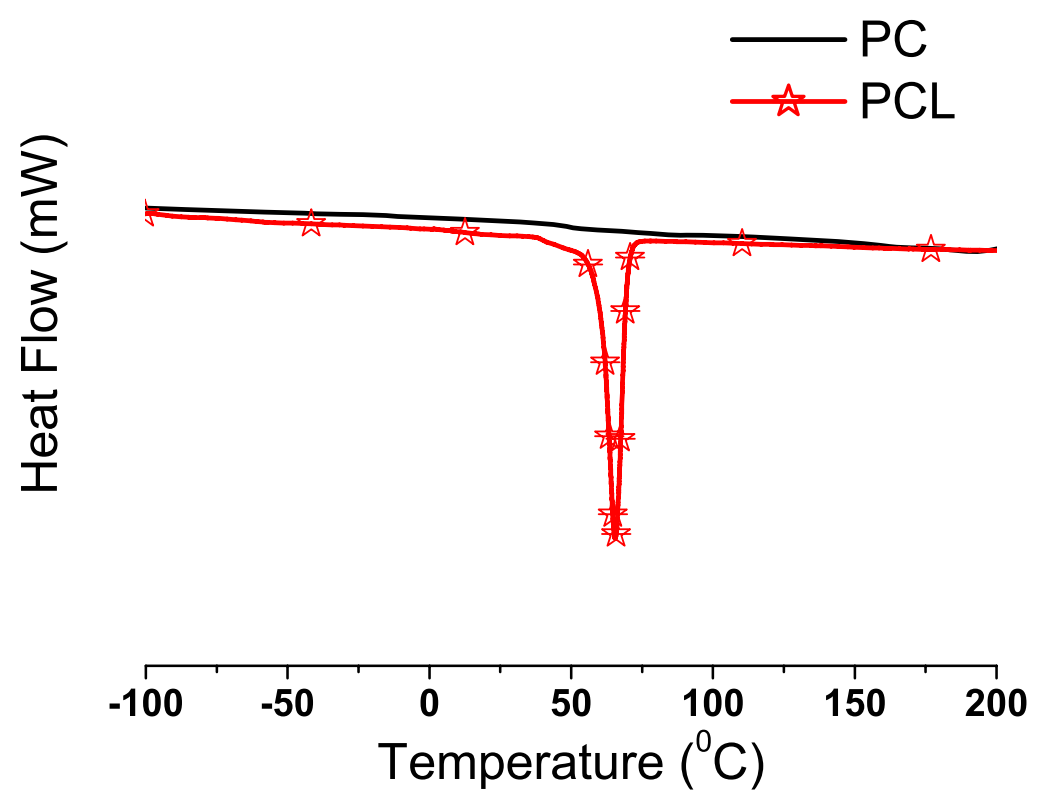

Figure 5. DSC profiles of PC/PCL blends.

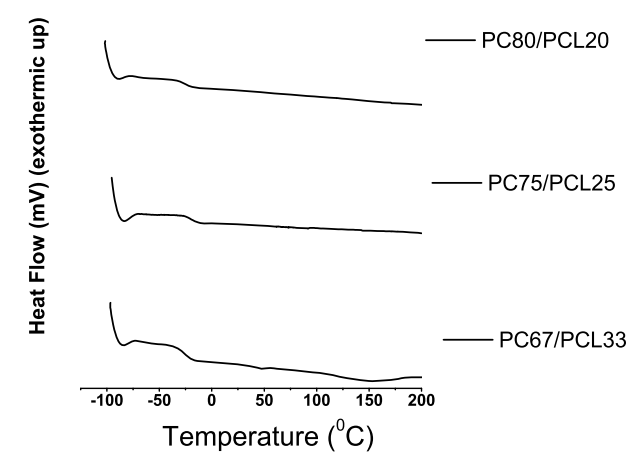


Table 7. $\mathrm{T}_{g}$ for the PC/PCL samples.

\begin{tabular}{lr}
\hline Sample & $\mathrm{T}_{g}\left({ }^{\circ} \mathrm{C}\right)$ \\
\hline PC80/PCL20 & -31 \\
PC75/PCL25 & -26 \\
PC67/PCL33 & -31 \\
\hline
\end{tabular}

Morphology

The SEM image of neat PC did not exhibit any porosity, whilst the PC/PCL samples were porous (Figure 6). Interconnected micro-pores were observed in the SEM images of the PC/PCL blends. The ability of $\mathrm{CO}_{2}$ to form pores and foam $\mathrm{PC}$ has been documented in the scientific literature [34-36]. Previously documented cases involved longer processing times, higher pressures and temperatures [34-36]. The formation of pores in the PC/PCL blends most likely occurred because of the ability of PCL to foam in the presence of $\mathrm{CO}_{2}$. From the SEM images of the PC/PCL blend surfaces it is evident that the sizes of the pores are in the micron range.

Figure 6. SEM image of (a) PC, (b) PC80/PCL20, (c) PC75/PCL25, (d) PC67/PCL33.

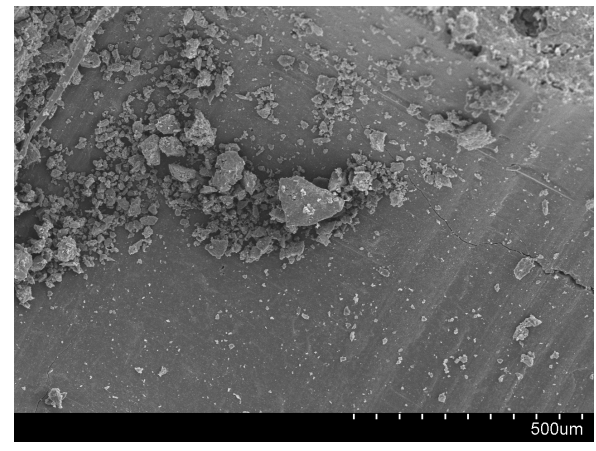

(a)

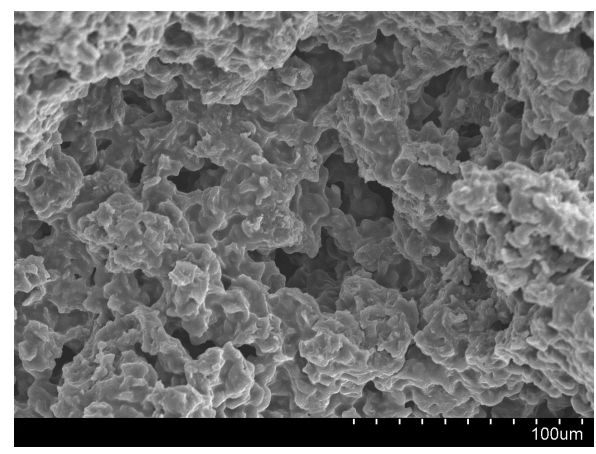

(c)

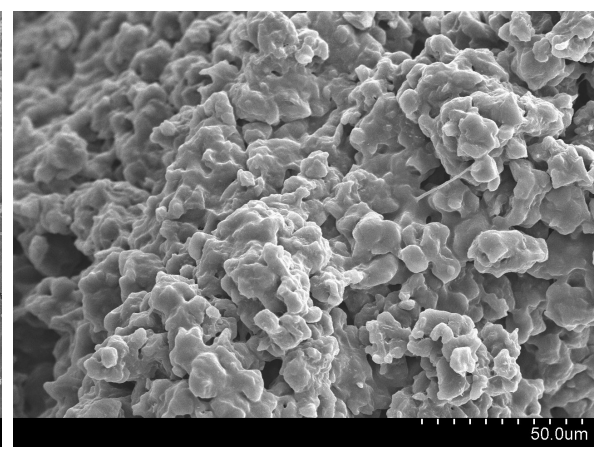

(b)

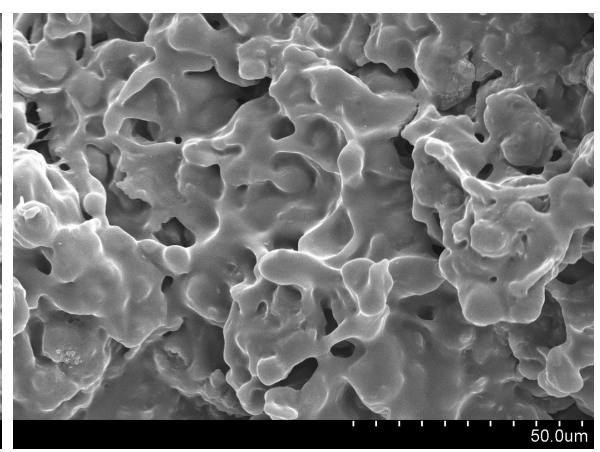

(d)

According to the International Union of Pure and Applied Chemistry (IUPAC), pores are classified into three ranges based on internal diameter; micropores, mesopores and macropores (Table 9) [37,38]. Each type of internal pore width exhibits a characteristic adsorption pattern. Also, IUPAC has classified 
the sorption isotherms into six groups based on their sorption patterns (Figure 9 [38]). Each of the adsorption isotherms in Figure 7 exhibited Type II sorption behaviour, which is typical of a macroporous adsorbent. Each PC/PCL adsorption isotherm exhibited some form of hysteresis. Hysteresis indicates that the adsorption and desorption of $\mathrm{N}_{2}$ molecules followed different pathways, and were possibly obstructed by the existence of interconnected pores. From the adsorption isotherms it is difficult to confidently quantify a pore width. However by analyzing the adsorption profile and comparing it against the IUPAC classified isotherms, one can confidently identify micropores, mesopores or macropores. Nitrogen adsorption is most accurate for quantifying pore sizes less than $300 \mathrm{~nm}$, and the SEM images (Figure 6) clearly indicate the existence of pores larger than $300 \mathrm{~nm}$. Also the adsorption/desorption isotherms of the PC/PCL blends clearly indicate a high incidence of macropores.

\subsection{Drug Loading and Dissolution}

Blend PC67/PCL33 (Table 1) was chosen as a candidate for drug-loading because of its porous morphology, morphology that was ideal for tissue engineering scaffold-type applications. The PC67/PCL33 blend had the highest fraction of PCL, and therefore the greatest potential for higher drug-loading compared to the PC80/PCL20 and PC75/PCL25.

The PCL component provided a pathway for the dense $\mathrm{CO}_{2}$ impregnation of ibuprofen. Ibuprofen is a $\mathrm{CO}_{2}$-soluble therapeutic agent [39]. Both the blend and a control sample of PCL were impregnated at $40{ }^{\circ} \mathrm{C}$ and 200 bar in $4 \mathrm{hrs}$, and drug loadings of $9 \mathrm{wt} \%$ and $20 \mathrm{wt} \%$ (Table 8) were observed. Polycaprolactone is susceptible to melting point depression in the presence of dense $\mathrm{CO}_{2}$ [40]. Despite the lower PCL content, the PC67/PCL33 had a higher drug-loading than pure PCL, which may be correlated to both the higher porosity and bumpy surface morphology (Figure 6). The pores may have provided a means for the solubilized ibuprofen to travel deeply into the PC/PCL matrix which had a larger surface area to adsorb onto.

Table 8. Drug loading after impregnation.

\begin{tabular}{lc}
\hline Sample & Drug Loading (wt $\%)$ \\
\hline PCL & 9 \\
PC67/PCL33 & 20 \\
\hline
\end{tabular}

Table 9. IUPAC classification of internal pore width.

\begin{tabular}{lc}
\hline Pore Classification & Definition \\
\hline Micropore & internal width $<2 \mathrm{~nm}$ \\
Mesopore & $2 \mathrm{~nm}<$ internal width $<50 \mathrm{~nm}$ \\
Macropore & internal width $>50 \mathrm{~nm}$ \\
\hline
\end{tabular}

A dissolution study was conducted to monitor the release profile of ibuprofen from the impregnated samples. The free ibuprofen dissolved completely in minutes (Figure 8), whereas the ibuprofen 
Figure 7. BET isotherms: (a)PC80/PCL20 (b)PC75/PCL25 (c)PC67/PCL33.

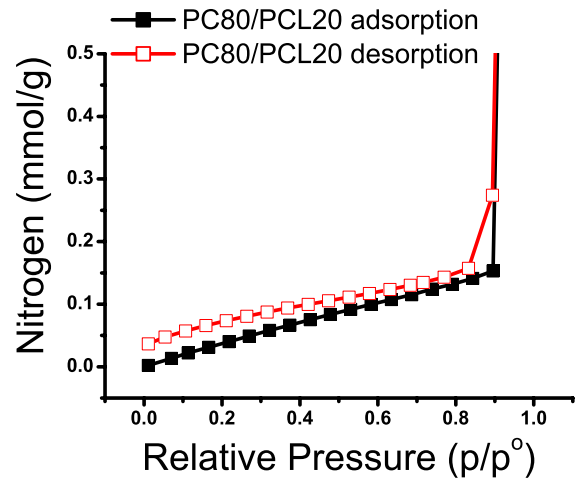

(a)

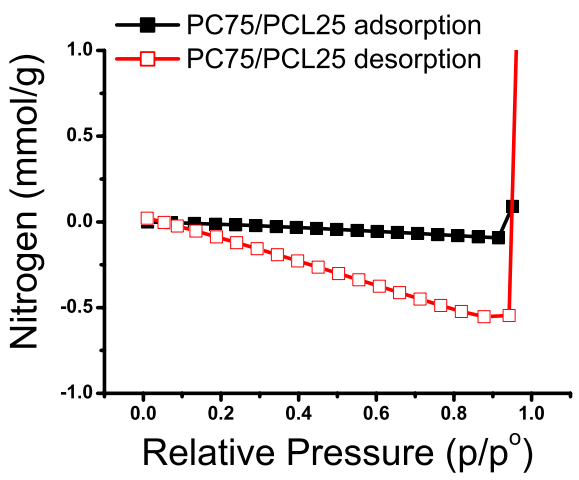

(b)

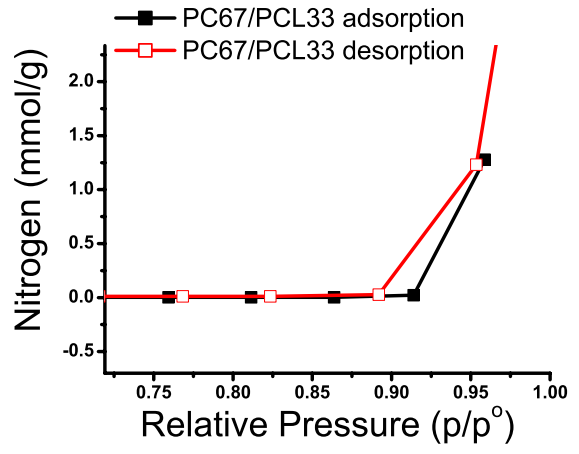

(c)

Figure 8. Dissolution profiles of free ibuprofen, PCL and PC67/PCL33.

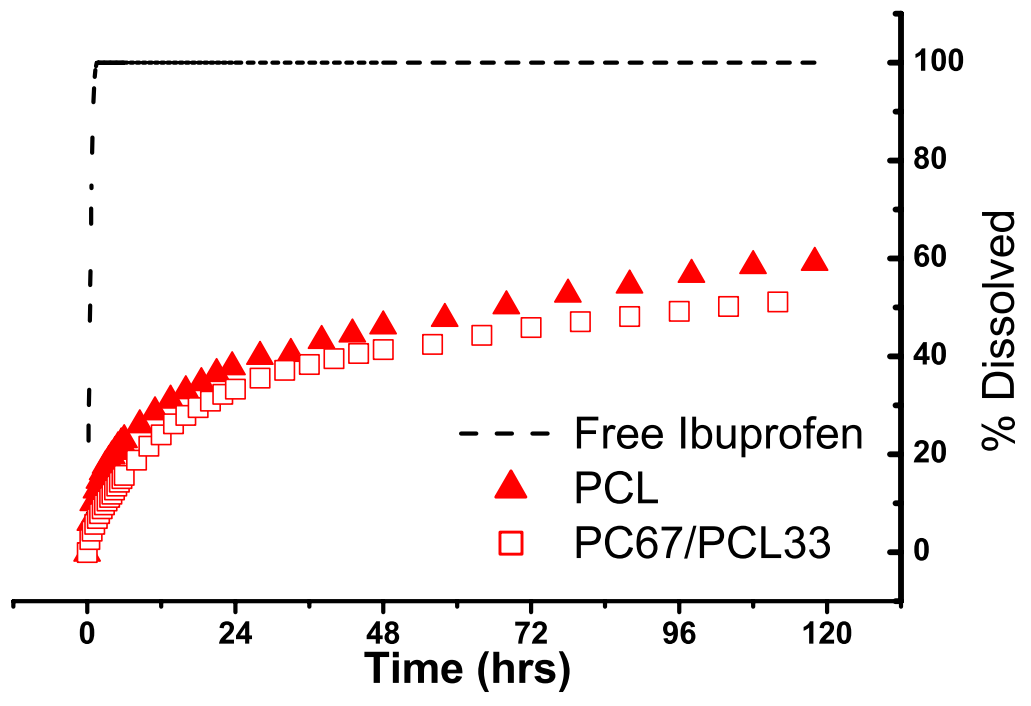

in the PCL and PC/PCL blend displayed a sustained release over days (Figure 8). After 5 days, approximately $60 \%$ and $50 \%$ of drug was released from PCL and PC67/PCL33 respectively. Both PCL and PC67/PCL33 exhibited first order dissolution profiles. In summary, the PC/PCL blends 
exhibited porosity and sustained drug release, thereby making them potential candidates for biomedical applications such as drug delivery devices and tissue scaffolding.
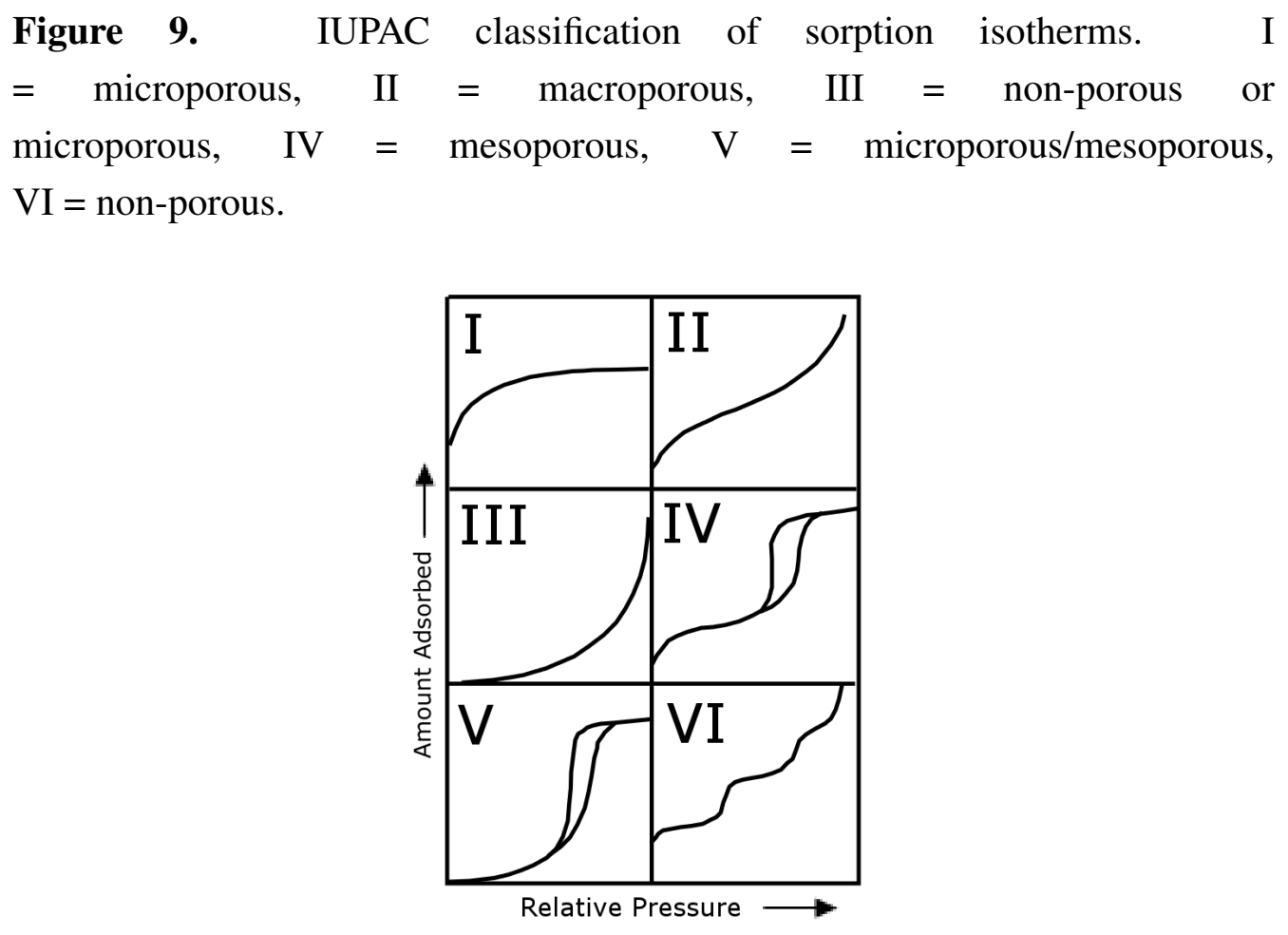

\section{Conclusion}

The use of dense $\mathrm{CO}_{2}$ as a polymerization medium to synthesize $\mathrm{PC}$, and then as a processing medium to create PC/PCL blends was proven to be successful in creating intimate bio-blends. A unique dense $\mathrm{CO}_{2}$ blending technique was used; the synthesis of PC in the presence of dense $\mathrm{CO}_{2}$-swollen PCL particles.

The three-stage melt-phase polymerization/blending method proved to be an advantageous use of dense $\mathrm{CO}_{2}$ for the production of macroporous PC/PCL blends. A macroporous architecture was observed for PC/PCL mass ratios of $80 / 20,75 / 25$ and 67/33. The DG synthesis of PC in the presence of PCL particles has proven to work as a blending technique, and selectively permits the synthesis of PC whilst extracting the phenol. Compared to already existing blending methods, DGT provides a more environmentally benign method void of organic solvents, and an alternative route to pore-formation void of toxic porogens.

Bio-blends of PC/PCL have potential industrial and biomedical applications. The biodegradability of PCL has long been exploited in drug delivery devices. In this work, ibuprofen, an anti-inflammatory agent was successfully impregnated into a macroporous PC/PCL blend. A drug-loading of $20 \mathrm{wt} \%$ was obtained using DGT. Also, a sustained release profile was observed over 5 days. Mechanical testing is advisable to further prove the industrial and biomedical applicability of DG produced PC/PCL blends. 


\section{Acknowledgements}

The authors wish to thank Mr. Peter Valtchev for his assistance in developing the RP-HPLC method for quantifying the monomer conversion and also to Dr. Un Teng Lam for her assistance with the dissolution apparatus. Also, financial support was provided by Australian Research Council Discovery Grant (Reference DP0665514).

\section{References}

1. Freitag, D.; Grigo, U.; Mueller, P.R.; Nouvertne, W. Polycarbonates. Encycl. Polym. Sci. Eng. 1987, 11, 648-718.

2. Fukuoka, S.; Kawamura, M.; Komiya, K.; Tojo, M.; Hachiya, H.; Hasegawa, K.; Aminaka, M.; Okamoto, H.; Fukawa, I.; Konno, S. A novel non-phosgene polycarbonate production process using by-product carbon dioxide as starting material. Green Chem. 2003, 5, 497-507.

3. Pohl, L.R.; Bhooshan, B.; Whittaker, N.F.; Krishna, G. Phosgene: A metabolite of chloroform. Biochem. Biophys. Res. Comm. 1977, 79, 684-691.

4. Gross, S.M.; Givens, R.D.; Jikei, M.; Royer, J.R.; Khan, S.; DeSimone, J.M.; Odell, P.G.; Hamer, G.K. Synthesis and swelling of poly (bisphenol A carbonate) using supercritical carbon dioxide. Macromolecules 1998, 31, 9090-9092.

5. Gross, S.M.; Roberts, G.W.; Kiserow, D.J.; DeSimone, J.M. Synthesis of highmolecular weight polycarbonate by solid-state polymerization. Macromolecules 2001, 34, 3916-3920.

6. Lee, J.-Y.; Song, C.-H.; Kim, J.-I.; Kim, J.-H. Preparation of aromatic polycarbonatenanoparticles using supercritical carbon dioxide. J. Nanopart. Res. 2002, 4, 53-59.

7. Xiao, Y.; Wu, Y.; Wang, C.; Ying, W. Synthesis of polycarbonatein supercritical carbon dioxide. J. Chem. Ind. Eng. (China) 2007, 58, 2403-2407.

8. Coutsikos, P.; Magoulas, K.; Tassios, D. Solubilities of phenolsin supercritical carbon dioxide. J. Chem. Eng. Data 1995, 40, 953-958.

9. Greco, R.S. Implantation Biology: The Host Response and Biomedical Devices; CRC Press: Boca Raton, FL, USA, 1994.

10. Busby, A.J.; Zhang, J.; Roberts, C.J.; Lester, E.; Howdle, S.M. Novel nanostructured polymeric composites of polycaprolactone and ultra-high molecular weight polyethylene via a supercritical-fluid route. Adv. Mater. 2005, 17, 364-36.

11. Shieh, Y.T.; Lin, Y.T. Transesterification and polymerization reactions of aliphatic polyesters in supercritical carbon dioxide fluids without the presence of a catalyst. Eur. Polym. J. 2007, 43, 1847-1856.

12. Mohamed, A.; Gordon, S.H.; Biresaw, G. Polycaprolactone/polystyrene bioblends characterized by thermogravimetry, modulated differential scanning calorimetry and infrared photoacoustic spectroscopy. Polym. Degrad. Stabil. 2007, 92, 1177-1185.

13. Yoganathan, R.; Mammucari, R.; Foster, N.R. Dense Gas Processing of Polymers. J. Polym. Rev. 2010, 50.144-177.

14. Yoganathan, R.; Mammucari, R.; Foster, N.R. Impregnation of Ibuprofen into Polycaprolactone Using Supercritical Carbon Dioxide. J. Phys. Conf. Ser. 2010, 215(012087). 
15. Paul, D.R.; Bucknall, C.B. Polymer Blends; Wiley: Chichester, UK, 1999.

16. Folkes, M.J.; Hope, P.S. Polymer blends and alloys; Blackie Academic \& Professional: New York, NY, USA, 1993.

17. Paul, D.R.; Newman, S. Polymer blends, Vol. 2; Newman, S. (ed.); Academic Press: New York, NY, USA, 1978.

18. Paul, D.R.; Newman, S. Paul, D.R. Polymer blends; Newman, S. (ed.); Academic Press: New York, NY, USA, 1978; Volume 1.

19. Tomasko, D.L.; Li, H.; Liu, D.; Han, X.; Wingert, M.J.; Lee, L.J.; Koelling, K.W. A review of carbon dioxide applications in the processing of polymers. Ind. Eng. Chem. Res. 2003, 42, 6431-6456.

20. Watkins, J.J.; McCarthy, T. J. Chemistry in supercritical fluid-swollen polymers: Direct synthesis of polymer/polymer and polymer/metal. Polym. Mater. Sci. Eng. 1995, 73 , 158-159.

21. Watkins, J.J.; McCarthy, T.J. Polymerizations in supercritical fluid-swollen polymers: A new route to polymer blends and composite foams. Polymer Preprints; American Chemical Society, Division of Polymer Chemistry: Ann Arbor, MI, USA, 1994; Volume 35, 699-700.

22. Watkins, J.J.; McCarthy, T.J. Polymerization in supercritical fluid-swollen polymers: A new route to polymer blends. Macromolecules 1994, 27, 4845-4847.

23. Li, D.; Han, B. Impregnation of polyethylene (PE) with styrene using supercritical $\mathrm{CO}_{2}$ as the swelling agent and preparation of PE/polystyrene composites. Ind. Eng. Chem. Res. 2000, 39, 4506-4509.

24. Guo, Z.; Wingert, M.J.; Shen, J.; Lee, L.J.; Tomasko, D.L. Foaming dynamics of immiscible polymer blends. Annual Technical Conference-ANTEC, Conference Proceedings 2007, 5, 2970-2975.

25. Li, H.; Lee, L.J.; Tomasko, D.L. Effect of carbon dioxide on the interfacial tension of polymer melts. Ind. Eng. Chem. Res. 2004, 43, 509-514.

26. Balsamo, V.; Calzadilla, N.; Mora, G.; Mueller, A.J. Thermal characterization of polycarbonate/polycaprolactone blends. J. Polym. Sci. B Polym. Phys. 2001, 39, 771-785.

27. Chun, Y.S.; Park, J.; Sun, J.B.; Kim, W.N. Blends of polycarbonate and poly(e-caprolactone) and the determination of the polymer-polymer interaction parameter of the two polymers. J. Polym. Sci. B Polym. Phys. 2000, 38, 2072-2076.

28. Gonzalez, I.; Eguiazabal, J.I.; Nazabal, J. New clay-reinforced nanocomposites based on a polycarbonate/polycaprolactone blend. Polym. Eng. Sci. 2006, 46, 864-873.

29. Hernandez, M.C.; Laredo, E.; Bello, A.; Carrizales, P.; Marcano, L.; Balsamo, V.; Grimau, M.; Muller, A.J. From miscible to immiscible polycarbonate/poly(e-caprolactone) blends. Macromolecules 2002, 35, 7301-7313.

30. Ketelaars, A.A.J.; Papantoniou, Y.; Nakayama, K. Analysis of the density and the enthalpy of poly(e-caprolactone)-polycarbonate blends: Amorphous phase compatibility and the effect of secondary crystallization. J. Appl. Polym. Sci. 1997, 66, 921-927.

31. Bailly, C.; Daoust, D.; Legras, R.; Mercier, J. P.; Strazielle, C.; Lapp, A. On the molecular weight determination of bisphenol-A polycarbonate. Polymer 1986, 27, 1410-1415. 
32. Kim, J.; Roberts, G.W.; Kiserow, D.J. Effect of prepolymer molecular weight on solid state polymerization of poly(bisphenol a carbonate) with nitrogen as a sweep fluid. J. Polym. Sci. A Polym. Chem. 2008, 46, 4959-4969.

33. Wang, J.; Cheung, M.K.; Yl, M. Miscibility and morphology in crystalline/amorphous blends of poly(caprolactone)/poly(4-vinylphenol) as studied by DSC, FTIR, and ${ }^{1} 3 \mathrm{C}$ solid state NMR. Polymer 2002, 43, 1357-1364.

34. Lee, J.W.S.; Wang, K.; Park, C. Challenge to extrusion of low-density microcellular polycarbonate foams using supercritical carbon dioxide. Ind. Eng. Chem. Res. 2005, 44, 92-99.

35. Wessling, M.; Borneman, Z.; Boomgaard van den, Th.;Smolders, C.A. Carbon dioxide foaming of glassy polymers. J. Appl. Polym. Sci. 1994, 53. 1497-1512.

36. Fleming, G.K.; Koros, W.J.; Dilation of substituted polycarbonates caused by high-pressure carbon dioxide sorption. Macromolecules 1990, 23, 1353-1360.

37. Langmuir, I. The adsorption of gases on plane surfaces of glass, mica and platinum. J. Am. Chem. Soc. 1918, 40, 1361-1402.

38. Lowell, S. Characterization of porous solids and powders: Surface area, pore Size, and Density; Kluwer Academic Publishers: Boston, MA, USA, 2004.

39. Charoenchaitrakool, M.; Dehghani, F.; Foster, N.R.; Chan, H.K. Micronization by rapid expansion of supercritical solutions to enhance the dissolution rates of poorly water-soluble pharmaceuticals. Ind. Eng. Chem. Res. 2000, 39, 4794-4802.

40. Lian, Z.; Epstein, S.A.; Blenk, C.W.; Shine, A.D. Carbon dioxide-induced melting point depression of biodegradable semicrystalline polymers. J. Supercrit. Fluid. 2006, 39, 107-117.

41. Korsmeyer, R.W.; Gurny, R.; Doelker, E. Mechanisms of solute release from porous hydrophilic polymers. Int. J. Pharm. 1983, 15, 25-35.

42. Peppas, N.A. Analysis of Fickian and non-Fickian drug release from polymers. Pharm. Acta Helv. 1985, 60, 110-111.

(C) 2010 by the authors; licensee MDPI, Basel, Switzerland. This article is an Open Access article distributed under the terms and conditions of the Creative Commons Attribution license http://creativecommons.org/licenses/by/3.0/. 